\title{
Examining the effects of exchange rates on Australian domestic tourism demand: A panel generalized least squares approach
}

\author{
Ghialy Yap ${ }^{\mathrm{a}}$ \\ ${ }^{a}$ School of Accounting, Finance and Economics, Faculty of Business and Law, Edith Cowan University, 270 \\ Joondalup Drive, Joondalup WA 6027, Western Australia \\ Email: c.yap@ecu.edu.au
}

\begin{abstract}
In Australia, domestic tourism generated AUD71 billion in 2009-10, representing approximately $75.6 \%$ of national tourism revenue. While the number of domestic overnight visitors increased by $2.3 \%$ in that year, the number of Australians travelling overseas grew by $15.9 \%$. This shows that there is a high tendency for more Australians to travel overseas. There are two possible reasons: first, the introduction of low cost carriers has induced cheaper flights to overseas, particularly from Australia to South East Asia; second, the dramatic appreciation of Australian dollars against major currencies, as well as the strong growth of Australian household income, have motivated more Australians to travel overseas rather than within their own country. The purpose of this study is to examine the economic factors that influence the demand for Australian domestic tourism. In particular, the research explores to what extent the appreciation of Australian dollar could affect the Australian domestic tourism industry, as measured by the number of nights spent by domestic holiday visitors, business travelers and visitors of friends and relatives (VFR) from quarter 1 of 1999 to quarter 4 of 2010. Furthermore, the study employs panel generalized least squares models because they take account of both heteroskedasticity and serial correlation to produce optimistic estimated standard errors. The empirical findings show that exchange rates could influence the decisions to travel domestically within Australia by holiday travellers. It is likely that Australians who are seeking holidays would prefer travelling overseas when the Australian dollar is high.
\end{abstract}

Keywords: Domestic tourism; Australia; Tourism Demand; Exchange rates; Panel generalized least squares 


\section{INTRODUCTION}

Australia is currently experiencing a resources boom due to increasing demand for coal and iron ore from Asia, particularly from China. The mining industry over four years tripled its export values, reaching at AUD117.6 billion in 2008-09 (ABS, 2010b). Because of the soaring mining exports, the Australian dollar has appreciated significantly with a record of nearly parity to the US dollar. Recently, the currency was traded around USD1.05 at the time this paper was written. Nevertheless, Australian tourism stakeholders have been expressing their concerns over whether the rising Australian dollar could hurt the country's tourism industry. The reasons are two-fold. First, the rising number of low-cost flight carriers in Australia and cheap international airfares could encourage more Australians to take a vacation at overseas destinations. Furthermore, as overseas tourism markets tend to offer cheaper tourism products with good value of money, more Australians would rather travel overseas than within their own country (Anonymous, 2010). Second, the appreciation of the Australian dollar increases the cost of inbound travel to Australia and hence, this may discourage potential foreign tourists to visit Australia. Overall, the rising values of the Australian dollar due to the mining resource boom create potential adverse effects on the country's tourism industry, particularly domestic tourism.

Domestic tourism in Australia plays a significant role in generating tourism revenue and employment opportunities. In 2010, domestic visitors ${ }^{1}$ spent AUD71 billion on Australian produced goods and services, representing approximately $75.6 \%$ of total tourism revenue in the country (ABS, 2010a). Furthermore, domestic tourists spent about 261 million nights travelling in Australia, which is about $41 \%$ more than the nights spent by international visitors in the year (RET, 2010a, 2010b). Furthermore, the aggregate domestic tourists' spending increased by $3.35 \%$ in 2010 compared to 2009 , which could be related to a surge in the consumption by domestic overnight and same-day visitors. Moreover, the strong growth in domestic tourist consumption may be the reason of an additional $1.3 \%$ jobs created in the industry in 2010 (ABS, 2010a). In conclusion, it is inevitable that domestic tourism dominates tourism businesses in Australia in terms of the country's total tourism revenue earned.

Referring to Figure 1, both domestic and Australian outbound tourist markets reacted strongly to the movements of exchange rate. Accordingly, when the Australian dollar appreciated against the US dollar particularly in 2008 and in 2010, the number of domestic overnight visitors dropped while the Australian outbound tourist numbers soared. In conclusion, the appreciation of Australian dollar may have encouraged more Australians to travel overseas; however, the consequence is that it may cause negative impacts on domestic tourist market.

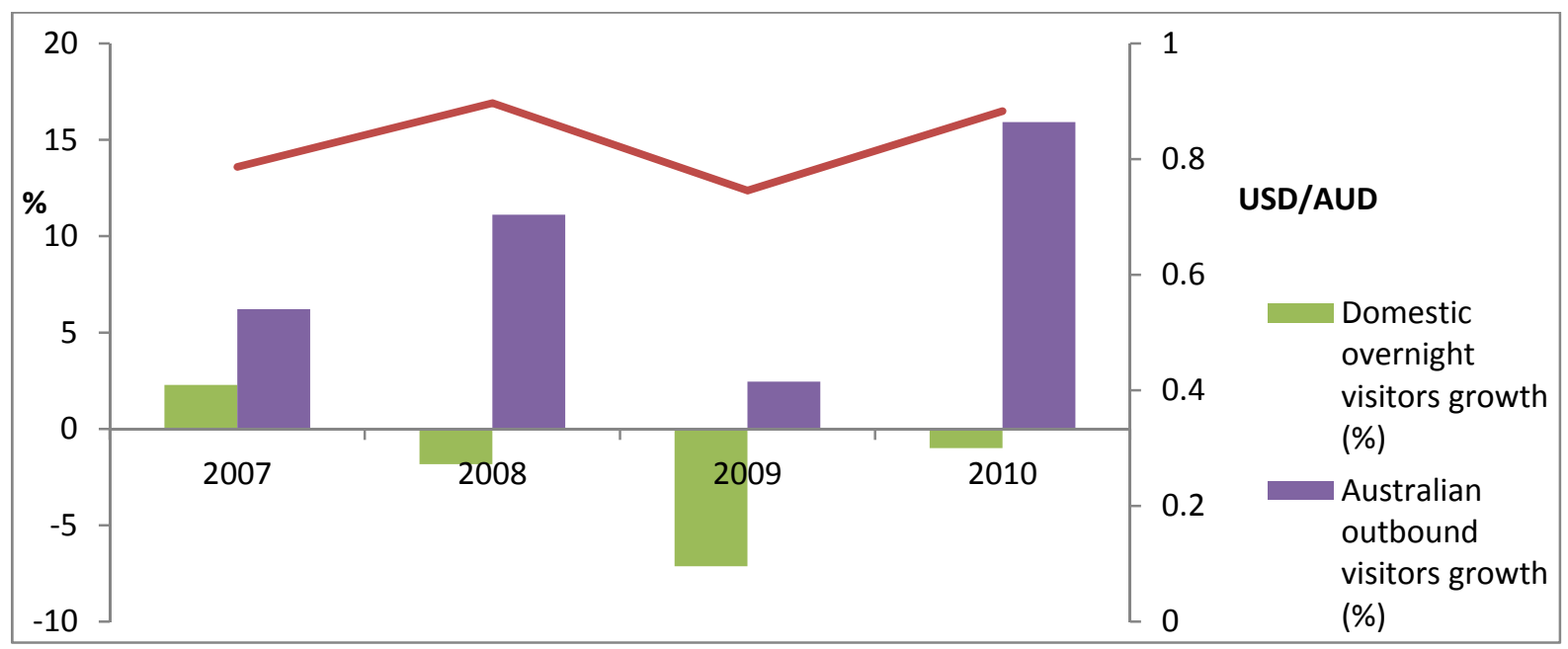

Figure 1. Domestic overnight tourism, Australian outbound tourism and US exchange rate, 2007-2010.

The purpose of this study is to examine the economic factors, particularly exchange rates, which may influence the demand for Australian domestic tourism. This research could recommend strategies for sustaining tourism businesses in Australia during mining boom periods.

\footnotetext{
${ }^{1}$ According to Tourism Research Australia, domestic visitors refers to Australian residents who are aged 15 years and over and have participated travel activities within Australia at least 50 kilometres and at least 4 hours away from home (RET, 2010b).
} 


\section{A PANEL DATA SPECIFICATION FOR AUSTRALIAN DOMESTIC TOURISM DEMAND}

This study models the demand for Australian domestic tourism and the indicators used are income earned by Australians, the prices of domestic travel, the prices of overseas travel, exchange rates, seasonality, and one-off events such as the 2002 Bali bombings incident. Moreover, in the tourism demand literature, an indicator of repeated visits is important for measuring to what extent travellers could re-visit a destination. To do that, many tourism researchers incorporated a lagged dependent variable to the tourism demand model (Brida \& Risso, 2009; Garin-Munoz, 2006; Yap \& Allen, 2011). This research uses first differenced logarithm variables to avoid panel non-stationarity issues (Garin-Munoz, 2006) and the coefficients can be interpreted as elasticities (Lim, 2006). In general, the panel data model is specified as:

$$
\begin{aligned}
& \Delta \ln D D T_{i t}=\alpha+\beta_{1} \Delta \ln R G D P_{i t}+\beta_{2} \Delta \ln P_{i t}+\beta_{3} \Delta \ln P C_{i t}+\beta_{4} \Delta \ln E R_{i t}+\beta_{5} \text { Seasonality }+\beta_{6} \text { Bali }+ \\
& \beta_{7} \Delta \ln D D T_{i t-1}+\beta_{8} \Delta \ln R G D P_{i t-1}+\beta_{9} \Delta \ln P_{i t-1}+\beta_{10} \Delta \ln P C_{i t-1}+\beta_{11} \Delta \ln E R_{i t-1}+\epsilon_{i t}
\end{aligned}
$$

where $\Delta$ denotes as first-difference; $\ln$ denotes as natural logarithm; $D D T_{i t}$ is the domestic visitor nights for each state $i$ at time $t ; R G D P_{i t}$ is Australia's real gross domestic product; $P_{i t}$ is price of domestic travel for each state $i$ at time $t ; P C_{i t}$ is price of overseas travel for each state $i$ at time $t ; E R_{i t}$ is exchange rates for each state $i$ at time $t$; $\epsilon_{i t}$ is the error term. Seasonality includes quarterly seasonal dummies and Bali denotes the incidence of Bali bombings in 2002.

The collected information is stacked into a panel data series which consists of six Australia States plus one Northern Territory and 47 quarterly time periods (June 1999 to December 2010). Based on the demand model (1), the proxy variables for the dependent variable are the number of domestic nights stayed by holiday-makers, visitors of friends and relatives (VFR) and business travellers. For the independent variables, the real gross domestic product (RGDP) is the proxy for income, while the consumer price index of domestic travel and accommodation $(\mathrm{P})$ is the indicator for price of domestic travel. To capture the effects of substitute products, the consumer price index of overseas travel and accommodation (PC) is used. Moreover, this study includes US dollar per Australian dollar currency as an indicator for exchange rates (ER). The underlying reason is that USD is the world's most widely traded currency and most foreign transactions recorded in Australia may be in USD. Seasonal dummy variables are used in this research to take account of the seasonal effects of domestic visitor nights. The tourism demand data are extracted from the quarterly reports of Travel by Australians which are published by the Department of Resources, Tourism and Energy. As for all independent variables, the data can be obtained from the websites of the Australian Bureau of Statistics.

\section{PANEL DATA REGRESSIONS}

In most cases, domestic tourism demand data tend to be small and the estimations using time-series often suffer from small-sample biases (Allen, Yap and Riaz, 2009). To overcome this issue, panel data are used because it contains more information and could generate more precise estimations than pure time-series (Baltagi, 2008). This study adopts panel generalised least squares (or panel GLS) regressions which allow estimation in the presence of autocorrelation within panels and heteroskedasticity across panels (STATA, 2009). There are three reasons for choosing these panel regressions in the current research. First, cross-sectional units may vary in size and the variance for each unit differs (Baltagi, 2008; STATA, 2009). Second, Baltagi (2008, p. 92) argued that the effects of autocorrelation should be considered when generating panel data estimations because any unobserved shock in the current period will affect the behavioural relationship for at least the next few periods. In general, this current research considers the issues of heteroskedasticity and serial correlation to prevent biased estimations of standard errors. Third, panel GLS regression tends to produce optimistic estimated standard errors as long as the number of time periods is more than the number of cross-section units (i.e. $\mathrm{T}>\mathrm{N}$ ) (Hoechle, 2007).

A general panel data regression can be written as follows:

$$
y_{i t}=\boldsymbol{x}_{\boldsymbol{i t}}^{\prime} \boldsymbol{\beta}+\alpha+\mu_{i}+\epsilon_{i t}
$$

where $i=1, \ldots, n$ is the number of units (or panels), $t=1, \ldots, T i$ is the number of observations for panel $i, y_{i t}$ is the dependent variable with $i$ panels and $t$ time, $\mu_{i}$ is a group-specific random element of each $i$-th observation and is constant overtime, $\alpha$ is the regression constant term and $\epsilon_{i t}$ is the regression error in each period $t$. There are $K$ regressors in $\boldsymbol{x}_{i t}$ and $\beta$ is the coefficient matrix. It is often argued that $\mu_{i}$ is heterogeneous because each 
cross-section (or panel) does not exhibit a constant variance (Baltagi, 2008; Greene, 2008). Moreover, many econometric textbooks suggest that $\epsilon_{i t}$ values are heteroskedastic and/or serially correlated. According to Baltagi (2008), ignoring the presence of heteroskedastic and/or serially correlated disturbances will generate inefficient standard errors even though the coefficients are consistent. Therefore, this study conducts two diagnostic tests to investigate whether the assumptions of homoskedasticity and no serial correlations hold. The first is a joint Lagrange multiplier test for homoskedasticity by Baltagi, Bresson \& Pirotte (2006). It starts with the specifications of $\sigma_{\epsilon_{i t}}^{2}=\sigma_{\epsilon}^{2} h_{\epsilon}\left(Z_{i t} \theta_{1}\right)$ and $\sigma_{\mu_{i t}}^{2}=\sigma_{\mu}^{2} h_{\mu}\left(F_{i} \theta_{2}\right)$, where $h_{\epsilon}$ and $h_{\mu}$ are the parametric functions of exogenous variables $Z_{i t}$ and $F_{i}$. The joint hypothesis is that $H o: \theta_{1}=\theta_{2}=0$ (Baltagi, Bresson, \& Pirotte, 2006). The second is Wooldridge's test for serial correlation. It employs the residuals from equation (1) in firstdifferences, as follows:

$$
\begin{aligned}
& \Delta y_{i t}=\Delta x_{i t} \beta+\Delta \epsilon_{i t} \\
& \hat{\varepsilon}_{i t}=\Delta \hat{\epsilon}_{i t}=\Delta y_{i t}-\Delta x_{i t} \hat{\beta}
\end{aligned}
$$

Central to Wooldrige's test procedure is that, if $\epsilon_{i t}$ are not serially correlated, $\operatorname{Corr}\left(\Delta \epsilon_{i t}, \Delta \epsilon_{i t-1}\right)=-0.5$. To do that, it regresses $\widehat{\varepsilon}_{\text {it }}$ on $\widehat{\varepsilon}_{\text {it-1 }}$, and tests whether the coefficient of the lagged residual (say, $\phi$ ) is equal to -0.5 (Drukker, 2003). The null hypothesis of Wooldridge's test is that Ho: $\phi=-0.5$ (i.e. no first-order autocorrelation).

At the preliminary stage, I conducted a panel data regression using ordinary least squares with the assumptions of homoskedastic variance and no autocorrelation. Due to limited space, the complete results are not shown in this paper but they can be obtained upon request. From Table 1, the diagnostic test results conclude that heteroskedastic variances exist for all types of domestic visitors, while serial correlation presents only in the VFR data at the $5 \%$ significance level.

Table 1. Results of diagnostic tests of heteroskedasticity and serial correlation

\begin{tabular}{|l|l|l|l|}
\hline Coefficient & Holiday & Business & VFR \\
\hline $\begin{array}{l}\text { Likelihood-ratio test for } \\
\text { heteroskedasticity }\end{array}$ & $\begin{array}{l}242.91 \\
(\mathrm{p} \text {-value }=0.0000)\end{array}$ & $\begin{array}{l}56.42 \\
(\mathrm{p} \text {-value }=0.0000)\end{array}$ & $\begin{array}{l}178.79 \\
(\mathrm{p} \text {-value }=0.0000)\end{array}$ \\
\hline $\begin{array}{l}\text { Wooldridge test for } \\
\text { autocorrelation in panel data }\end{array}$ & $\begin{array}{l}0.908 \\
(\mathrm{p} \text {-value }=0.3775)\end{array}$ & $\begin{array}{l}2.873 \\
(\mathrm{p} \text {-value }=0.1410)\end{array}$ & $\begin{array}{l}6.994 \\
(\mathrm{p} \text {-value }=0.0383)\end{array}$ \\
\hline
\end{tabular}

Note: The results are based on panel data regressions using ordinary least squares with the assumptions of homoskedastic variance and no autocorrelation. The null hypothesis for heteroskedasticity test is that the regression variance is homoskedastic. Figures in brackets for the coefficients are standard errors. $* * *, * *$ and $*$ denotes the significance levels at $1 \%, 5 \%$ and $10 \%$, respectively. The null hypothesis for the Wooldridge test is that there is no first-order autoregression in the panel data regression.

Since the study has detected the existence of heteroskedasticity and serial correlation in the panel OLS regression, feasible generalized least square (FGLS) regressions are conducted to take account of these issues and correct the estimations. The procedures of FGLS can be explained as below:

Let $\bar{y}_{i t}=\overline{\boldsymbol{x}}_{\boldsymbol{i}}^{\prime} \boldsymbol{\beta}+\alpha+\mu_{i}+\bar{\epsilon}_{i t}$

Taking deviations between equations (1) and (2) removes the heterogeneity of $\mu_{i}$. Hence, the deviation equation is written as:

$$
y_{i t}-\bar{y}_{i t}=\left(\boldsymbol{x}_{i t}^{\prime}-\overline{\boldsymbol{x}}_{\boldsymbol{i t}}^{\prime}\right) \boldsymbol{\beta}+\left(\epsilon_{i t}-\bar{\epsilon}_{i t}\right)
$$

Equation (3) becomes a least squares dummy variable (or fixed effects) model, where the estimator is generally consistent and unbiased (Greene, 2008). Using the residuals of equation (3) and correcting the degrees of freedom, the estimated variance is given as:

$$
\hat{\sigma}_{\epsilon}^{2}=\frac{\sum_{i=1}^{n} \sum_{t=1}^{T}\left(\hat{\epsilon}_{i t}^{*}-\overline{\hat{\epsilon}}_{i t}^{*}\right)^{2}}{n T-n-K}, \text { where } \epsilon_{i t}^{*}=\epsilon_{i t}-\bar{\epsilon}_{i t}
$$

Next, $\hat{\sigma}_{\mu}^{2}$ is estimated. From equation (1), assume that $e_{i t}=\mu_{i}+\epsilon_{i t}$ and $\boldsymbol{e}=y_{i t}-\boldsymbol{x}_{\boldsymbol{i t}}^{\prime} \widehat{\boldsymbol{\beta}}-\hat{\alpha}$ in matrix form. Hence, the estimation variance for equation (1) is written as: 


$$
\text { plim } \sigma_{e}^{2}=p l i m \frac{e^{\prime e}}{n T-K-1}=\sigma_{\epsilon}^{2}+\sigma_{\mu}^{2}
$$

Therefore, given equations (5), $\hat{\sigma}_{\mu}^{2}=\hat{\sigma}_{e}^{2}-\hat{\sigma}_{\epsilon}^{2}$ (Green, 2008), the generalized least squares (GLS) estimator of $\widehat{\boldsymbol{\beta}}$ is:

$$
\widehat{\boldsymbol{\beta}}=\left(\boldsymbol{X}^{\prime} \boldsymbol{\Omega}^{-1} \boldsymbol{X}\right)^{-1} \boldsymbol{X}^{\prime} \boldsymbol{\Omega}^{-1} \boldsymbol{y}
$$

As the variance of GLS is $\operatorname{Var}\left(e_{i t}\right)=\sigma_{\mathrm{i}}^{2}$, the adjusted heteroskedasticity across panels, $\boldsymbol{\Omega}$, can be written as:

$$
\boldsymbol{\Omega}=\left[\begin{array}{cccc}
\sigma_{1}^{2} \mathrm{I} & 0 & \cdots & 0 \\
0 & \sigma_{2}^{2} \mathrm{I} & \cdots & 0 \\
\vdots & \vdots & \ddots & \vdots \\
0 & 0 & \cdots & \sigma_{\mathrm{K}}^{2} \mathrm{I}
\end{array}\right]
$$

Furthermore, this research considers the effects of serial correlation in panel data regression and the autoregressive process of order one $\mathrm{AR}(1)$ is assumed. Referring to equation (1), the regression error terms follow an $\mathrm{AR}(1)$ process which is:

$$
\epsilon_{i t}=\rho \epsilon_{i t-1}+v_{i t}
$$

where $v_{i t} \sim I I D\left(0, \sigma_{v}^{2}\right)$ and $|\rho|<1$. According to Baltagi (2008), the $\mu_{i}$ in equation (1) is independent of $\epsilon_{i t}$ and $\epsilon_{i 0} \sim\left(0, \frac{\sigma_{v}^{2}}{1-\rho^{2}}\right)$. The estimation of $\rho$ can also be conducted using the within residuals $\left(\tilde{\epsilon}_{i t}\right)($ Baltagi \& Li, 1991), as follows:

$$
\hat{\rho}=\frac{\sum_{i=1}^{N} \sum_{t=2}^{T} \tilde{\epsilon}_{i t} \tilde{\epsilon}_{i t-1}}{\sum_{i=1}^{N} \sum_{t=2}^{T} \tilde{\epsilon}_{i t-1}^{2}}
$$

This study applies the Prais-Winsten (PW) transformation method because it is found robust for small $T$ data (Baltagi, 2008, p. 93).

\section{EMPIRICAL RESULTS}

Table 2 provides the results of FGLS regressions, for domestic visitor nights by holiday (HOL), business (BUS) and visitors of friends and relatives (VFR), which have adjusted heteroskedasticity and serial correlation. The table also includes the results of FGLS heteroskedasticity-adjusted and panel Prais-Winsten regressions for the VFR tourism data.

From the table, some of the coefficient signs are found to be inconsistent with the economic theory. For instance, the coefficient of domestic tourism prices is 1.32 and is statistically significant at $1 \%$ level $^{1}$. This may imply that an increase in domestic tourism price will not cause the demand for holiday trips to fall. Perhaps, the rationale behind this result could be that these visitors were not aware of the price increase when they made their last-minute reservations for their trips. Similarly, for the business visitor case, the coefficient signs for RGDP and $\mathrm{P}$ variables contradict with the existing economic theory. In fact, there seems a mixture of evidence about the coefficient signs for RGDP and one-lagged RGDP. The study shows that the coefficient of RGDP for BUS is -7.12 , and this is statistically significant at the $1 \%$ critical level. Nevertheless, as for the one-lagged RGDP, the variable is found to be positive and statistically insignificant when the panel FGLS regression with heteroskedasticity is used. Furthermore, the one-lagged $\mathrm{P}$ coefficient for domestic business visitor data has a positive sign, indicating that an increase in the domestic travel price did not instigate the fall in the number of business travellers. A possible justification for this result is that business visitors are less sensitive to the price changes because their companies may support all travel expenses for business purposes.

\footnotetext{
1 The study has conducted a simple calculation of correlation between the data on domestic holiday visitor nights and domestic tourism prices, and has found that the correlation value is positive $(0.6764)$.
} 
Yap, G., Examining the Effects of Exchange Rates on Australian Domestic Tourism Demand...

Table 2. Panel FGLS Regressions

\begin{tabular}{|c|c|c|c|c|}
\hline \multirow[t]{2}{*}{ Coefficient } & \multirow{2}{*}{$\begin{array}{l}\Delta \ln H O L_{i t} \\
\begin{array}{l}\text { Heteroskedasticity } \\
\text { adjusted }\end{array}\end{array}$} & \multirow{2}{*}{$\begin{array}{l}\Delta \ln B U S_{i t} \\
\begin{array}{l}\text { Heteroskedasticity } \\
\text { adjusted }\end{array}\end{array}$} & \multicolumn{2}{|c|}{$\Delta \ln V F R_{i t}$} \\
\hline & & & $\begin{array}{l}\text { Heteroskedasticity } \\
\text { adjusted }\end{array}$ & $\begin{array}{ll}\text { Serial } & \text { correlation } \\
\text { adjusted } & \end{array}$ \\
\hline Constant & $\begin{array}{l}0.0235 \\
(0.0339)\end{array}$ & $\begin{array}{l}-0.0009 \\
(0.0417)\end{array}$ & $\begin{array}{l}0.0959 * * \\
(0.0408)\end{array}$ & $\begin{array}{l}-0.1538^{*} \\
(0.0789)\end{array}$ \\
\hline$\Delta \ln R G D P_{i t}$ & $\begin{array}{l}-0.5447 \\
(1.9236)\end{array}$ & $\begin{array}{l}-7.1169 * * * \\
(2.5643)\end{array}$ & $\begin{array}{l}-0.1997 \\
(2.4026)\end{array}$ & $\begin{array}{l}-1.2314 \\
(4.6854)\end{array}$ \\
\hline$\Delta \ln P_{i t}$ & $\begin{array}{l}1.3201 * * * \\
(0.3762)\end{array}$ & $\begin{array}{l}0.4238 \\
(0.3986)\end{array}$ & $\begin{array}{l}0.3577 \\
(0.4365)\end{array}$ & $\begin{array}{l}4.0111 * * * \\
(0.8335)\end{array}$ \\
\hline$\Delta \ln P C_{i t}$ & $\begin{array}{l}-0.4792 \\
(0.3803)\end{array}$ & $\begin{array}{l}0.5924 \\
(0.449)\end{array}$ & $\begin{array}{l}1.01 * * \\
(0.4474)\end{array}$ & $\begin{array}{l}0.441 \\
(0.8989)\end{array}$ \\
\hline$\Delta \ln E R_{i t}$ & $\begin{array}{l}-0.2849^{*} \\
(0.1634)\end{array}$ & $\begin{array}{l}0.3123 \\
(0.2131)\end{array}$ & $\begin{array}{l}-0.0079 \\
(0.2046)\end{array}$ & $\begin{array}{l}-0.448 \\
(0.3976)\end{array}$ \\
\hline Lagged dependent variable & $\begin{array}{l}-0.4103 * * * \\
(0.056)\end{array}$ & $\begin{array}{l}-0.4867 * * * \\
(0.0505)\end{array}$ & $\begin{array}{l}-0.4288 * * * \\
(0.0629)\end{array}$ & $\begin{array}{l}-0.4522 * * * \\
(0.1019)\end{array}$ \\
\hline$\Delta \ln R G D P_{i t-1}$ & $\begin{array}{l}-3.4439 \\
(2.2285)\end{array}$ & $\begin{array}{l}2.9094 \\
(2.9157)\end{array}$ & $\begin{array}{l}-1.8789 \\
(2.7104)\end{array}$ & $\begin{array}{l}0.6194 \\
(5.6212)\end{array}$ \\
\hline$\Delta \ln P_{i t-1}$ & $\begin{array}{l}0.1333 \\
(0.3839)\end{array}$ & $\begin{array}{l}0.3652 \\
(0.3997)\end{array}$ & $\begin{array}{l}0.0943 \\
(0.4137)\end{array}$ & $\begin{array}{l}0.0439 \\
(0.8415)\end{array}$ \\
\hline$\Delta \ln P C_{i t-1}$ & $\begin{array}{l}-0.2738 \\
(0.2435)\end{array}$ & $\begin{array}{l}-0.3717 \\
(0.3121)\end{array}$ & $\begin{array}{l}-0.0109 \\
(0.2881)\end{array}$ & $\begin{array}{l}-0.3783 \\
(0.6178)\end{array}$ \\
\hline$\Delta \ln E R_{i t-1}$ & $\begin{array}{l}0.1403 \\
(0.2227)\end{array}$ & $\begin{array}{l}-0.1732 \\
(0.2894)\end{array}$ & $\begin{array}{l}0.2791 \\
(0.2734)\end{array}$ & $\begin{array}{l}0.6226 \\
(0.5352)\end{array}$ \\
\hline$S 2$ & $\begin{array}{l}-0.2494 * * * \\
(0.0494)\end{array}$ & $\begin{array}{l}0.0371 \\
(0.0477)\end{array}$ & $\begin{array}{l}-0.2615 * * * \\
(0.0484)\end{array}$ & $\begin{array}{l}0.1227 \\
(0.0898)\end{array}$ \\
\hline $\begin{array}{l}S 3 \\
\text { Bali }\end{array}$ & $\begin{array}{l}-0.277 * * * \\
(0.0378)\end{array}$ & $\begin{array}{l}0.2018 * * * \\
(0.0379) \\
0.0707 * \\
(0.0368)\end{array}$ & $\begin{array}{l}-0.2783 * * * \\
(0.0395)\end{array}$ & $\begin{array}{l}-0.0311 \\
(0.0783)\end{array}$ \\
\hline $\begin{array}{l}\text { Chi-square statistics for the } \\
\text { overall (joint) significance } \\
\text { hypothesis }\end{array}$ & $\begin{array}{l}935.06 \\
(p-\text { value }=0.0000)\end{array}$ & $\begin{array}{l}172.11 \\
(p-\text { value }=0.0000)\end{array}$ & $\begin{array}{l}276.31 \\
(p-\text { value }=0.000)\end{array}$ & $\begin{array}{l}66.47 \\
(p-\text { value }=0.0000)\end{array}$ \\
\hline
\end{tabular}

Note: $\Delta$ denotes as first-difference; HOL denotes holiday visitor nights data; BUS denotes business visitor nights data; VFR denotes visitor nights by travellers who visited friends and relatives; $\mathrm{P}$ is the price of domestic holiday and accommodation; PC is the price of overseas holiday and accommodation; ER is the exchange rates (USD/AUD); RGDP is real gross domestic product; S2 is a seasonal dummy for the $2^{\text {nd }}$ quarter of the year; S3 is a seasonal dummy for the $3^{\text {rd }}$ quarter of the year. The null hypothesis for heteroskedasticity test is that the regression variance is homoskedastic. Figures in brackets for the coefficients are standard errors. ***, ** and * denotes the significance levels at $1 \%, 5 \%$ and $10 \%$, respectively. Based on Table 1 , heteroskedasticity was detected for HOL, BUS and VFR, whereas serial correlation was found only in VFR. Hence, the panel FGLS with heteroskedasticity adjusted are used for HOL, BUS and VFR, but the panel FGLS with serial correlation adjusted is used only for VFR.

For the domestic holiday visitor data, the exchange rates variable has a negative sign and is found statistically significant at $10 \%$ level. This variable can be one of the important indicators to predict domestic holiday tourism demand and the depreciation of US dollar can lead to a decline in the demand for domestic holidays in Australia. Conversely, the coefficient of exchange rates for the domestic business visitor data has a positive sign but is not statistically significant.

Other coefficients are also found to be statistically significant. For business travellers, the incidence of Bali bombings will increase the number of business visitor nights by up to $0.07 \%$. The fear of Bali bombings may have an adverse effect on business persons travelling overseas, but it has a positive impact on the demand for domestic business travel. Furthermore, the table also shows that the lagged dependent variable for domestic holiday and business visitor nights are negative and statistically significant. This indicates that these two groups of visitors may not repeat their travel every quarter. However, the seasonal dummy variables are found to have strong impacts on the demand for domestic holiday and business tourism, showing that these visitors tend to travel in particular seasons.

For the VFR data, the panel FGLS outcomes, with both heteroskedasticity and serial correlation adjusted regressions, provide rather mixed results. While the domestic price variable is found to be statistically significant in the panel Prais-Winsten regression, overseas prices and seasonal dummies variables are statistically significant only for the panel FGLS with heteroskedasticity adjusted regression. The coefficients of overseas prices are positive for VFR visitors, indicating that an overseas trip is a substitute product for domestic travel. Nevertheless, the coefficient of domestic price variables has a positive sign and is (again) inconsistent with the economic theory. Moreover, the study finds that the seasonal dummy variables (S2 and S3) have negative signs, implying that there is evidence of declining number of VFR visitor nights in the second and third quarters of the year. It makes sense as the low cost of overseas travel may induce more VFR visitors to travel overseas rather than visit families and friends domestically. Finally, exchange rate did not have any significant effect on the demand for domestic VFR travel. 


\section{CONCLUDING REMARKS}

This study investigated whether exchange rates have significant impacts on the demand for domestic travel. From the empirical findings, there is evidence that exchange rates could influence holiday travellers' decisions to travel domestically within Australia. However, the appreciation of Australian dollar did not have significant impact on other traveller groups such as business visitors and VFR. Hence, such findings may have some important implications for tourism policy-makers. Notwithstanding the potential loss of domestic holiday visitors during the period of strong Australian dollar, tourism operators could promote short-distance or weekend trips to VFR travellers at discounted prices and also promote more conferences for local and interstate business persons.

The current research encountered issues of incorrect coefficient signs. Most of the results suggested that the signs of domestic travel prices are positive which challenged the existing economic theory. The rationale behind this could be that airlines tend to charge high airfares when flights are near to actual departure dates. Probably, many travellers may make last-minute flight bookings online and they may not be aware of the price increase. Perhaps, this kind of social behaviour may require justifications using theories from consumer psychological perspectives.

\section{REFERENCES}

ABS. (2010a). Australian National Accounts: Tourism Stellite Account, 2009-10. Retrieved 15 December 2010. from http://www.abs.gov.au/AUSSTATS/abs@.nsf/MF/5249.0.

ABS. (2010b). Mining Statistics Newsletter, 2009 to 2010. Retrieved 10 June 2010. from http://www.abs.gov.au/ausstats/abs@.nsf/Latestproducts/8418.0Main\%20Features62009\%20to\%20201 0 ? opendocument\&tabname $=$ Summary\&prodno $=8418.0 \&$ issue $=2009 \% 20$ to $\% 202010 \&$ num $=\& v i e w=\#$.

Anonymous. (2010). Interest rate decision impacts tourism. Retrieved 17 January 2011, from http://www.asb.unsw.edu.au/newsevents/mediaroom/media/2010/march/Pages/interestratetourism.aspx

Baltagi, B. H. (2008). Econometric Analysis of Panel Data. West Sussex: Wiley.

Baltagi, B. H., Bresson, G., \& Pirotte, A. (2006). Joint LM test for homoskedasticity in a one-way error component model. Journal of Econometrics, 134(2), 401-417.

Baltagi, B. H., \& Li, Q. (1991). A transformation that will circumvent the problem of autocorrelation in an error component model. Journal of Econometrics, 48(3), 385-393.

Brida, J. G., \& Risso, W. A. (2009). A dynamic panel data study of the German demand for tourism in South Tyrol. tourism and Hospitality Research, 9(4), 305-313.

Drukker, D. M. (2003). Testing for serial correlation in linear panel-data models. STATA Journal, 3(2), 168-177.

Garin-Munoz, T. (2006). Inbound international tourism to Canary Islands: A dynamic panel data model. Tourism Management, 27(2), 281-291.

Greene, W. H. (2008). Econometric Analysis (6th ed.). New Jersey: Pearson Education.

Hoechle, D. (2007). Robust standard errors for panel regressions with cross-sectional dependence. STATA Journal, 7(3), 281-312.

RET. (2010a). International visitors in Australia, September 2010. Retrieved December 2010. from http://www.ret.gov.au/tourism/Documents/tra/International\%20Visitor\%20Survey/International\%20Vi sitors\%20in\%20Australia,\%20September\%20Quarter\%202010.pdf.

RET. (2010b). Travel by Australians, September 2010. Retrieved December 2010. from http://www.ret.gov.au/tourism/Documents/tra/National\%20Visitor\%20Survey/Travel by_Australians - September_Quarter_2010_FINAL.pdf.

STATA. (2009). Longitudinal Data/ Panel Data: Reference Manual Release 11. Texas: STATA Press.

Yap, G., \& Allen, D. (2011). Investigating other leading indicators influencing Australian domestic tourism demand. Mathematics and Computers in Simulation, 81(7), 1365-1374. 